\title{
Determination of Whole-Cell Fatty Acid Profiles for the Characterization and Differentiation of Isolates of Rhizoctonia solani AG-4 And AG-7
}

\author{
R. E. Baird, Entomology and Plant Pathology Department, Mississippi State University, Mississippi State 39762; \\ R. D. Gitaitis, Plant Pathology Department, University of Georgia, CPES, Tifton 31793; D. E. Carling, Agricul- \\ tural and Forestry Experiment Station, University of Alaska-Fairbanks, Palmer 99645; S. M. Baird, Entomology \\ and Plant Pathology Department, Mississippi State University; P. J. Alt, Plant Pathology Department, Mississippi \\ State University; and B. G. Mullinix, Experimental Statistics Unit, University of Georgia, CPES
}

\begin{abstract}
Baird, R. E., Gitaitis, R. D., Carling, D. E., Baird, S. M., Alt, P. J., and Mullinix, B. G. 2000. Determination of whole-cell fatty acid profiles for the characterization and differentiation of isolates of Rhizoctonia solani AG-4 and AG-7. Plant Dis. 84:785-788.

Fatty acid methyl esters (FAMEs) of isolates of Rhizoctonia solani AG-4 and AG-7 were characterized by gas chromatography and analyzed with Microbial Identification System software. Palmitic, stearic, and oleic acids were common in all isolates from both anastomosis groups (AGs) and accounted for $95 \%$ of the $\mathrm{C} 14$ to $\mathrm{C} 18$ fatty acids present. Oleic acid, most common in both $R$. solani AG-4 and AG-7 isolates, accounted for the greatest percentages of total FAMEs. The presence, quantities, or absence of individual fatty acids could not be used for distinguishing AG-4 and AG-7 isolates. Anteisopentadecanoic and 9-heptadecanoic acids, however, were specific to all three AG-7 isolates from Japan but absent in other AG-7 isolates and all AG-4 isolates. Pentadecanoic acid occurred in only two of the $R$. solani AG-4 isolates, but was not found in any of the AG-7 isolates. The AG-4 isolates could be distinguished from AG-7 isolates when quantities of FAMEs and key FAME ratios were analyzed with cluster analysis and principle components were plotted. Isolates of AG-7 from Arkansas, Indiana, and Georgia appeared to be more closely related to each other than to AG-7 isolates from Japan and Mexico. These differences in FAMEs were sufficiently distinct that isolate geographical variability could be determined. A dendrogram analysis cluster constructed from the FAMEs data showed results similar to that of the principal component analysis. Euclidean distances of total AG-4 isolates were distinct from total AG-7 isolates. The Arkansas and Indiana AG-7 isolates had a similar Euclidean distance to each another but the percentages were different for the AG-7 isolates from Japan and Mexico. In conclusion, variability of the FAMEs identified in this study would not be suitable as the main diagnostic tool for distinguishing individual isolates of $R$. solani AG4 from AG-7.
\end{abstract}

Rhizoctonia solani Kühn (teleomorph = Thanatephorus cucumeris (A. B. Frank) Donk) is a major soilborne pathogen that attacks agricultural crops worldwide (16). A species complex (12), R. solani has been subdivided, based on vegetative incompatibility interactions, into 12 anastomosis groups (AG-6).

Many $R$. solani AGs have been identified previously in North America and the most economically important groups occur throughout the continent. Several AGs are rare and infrequently reported, perhaps due to misidentification or restricted host range. For example, $R$. solani AG-7 was first reported in Arkansas on cotton (Gossypium hirsutum L.), soybean (Glycine $\max (\mathrm{L}$.) Merrill), rice (Oryza sativa

Corresponding author: R. E. Baird

E-mail: rbaird@plantpath.msstate.edu

Accepted for publication 31 March 2000.

Publication no. D-2000-0515-02R

(C) 2000 The American Phytopathological Society
L.), and radish (Raphanus sativus L.) (14). Symptoms induced by isolates of AG-7 from Arkansas included hypocotyl discoloration, cortical cell lesions, shortened apices, and severe stunting or death of the plants. Within a year of the first report, $R$. solani AG-7 was detected on watermelon (Citrullus lanatus (Thunb.) Matsum. \& Nakai) roots in Indiana (1). In field trials, severe hypocotyl and root lesions were observed on cotton and watermelon, but only minor hypocotyl damage was noted on soybean (2). Isolates of $R$. solani AG-4 and AG-7 have similar host ranges, cultural morphologies, and produce similar symptoms; therefore, AG-7 isolates in the United States may have been mistakenly identified as AG-4 (D. E. Carling, personal observation).

Anastomosis grouping is one of the most common methods used to specifically identify isolates of $R$. solani (4). This method, however, can be difficult when paired isolates vary in ability to form hyphal anastomosis. Because of the difficulties, additional criteria that complement the results of anastomosis pairing are needed.
Techniques including isozymes polymorphism and DNA analyses have been successfully employed to characterize specific and intraspecific isolates of fungi $(3,12)$. Similar studies have shown that genetic diversity occurs among isolates of $R$. solani AGs, including AG-2 and AG-9 $(5,11)$. To date, however, practical application of these methods for use in identification of fungi by diagnostic laboratories have been limited.

Fatty acid methyl ester (FAME) determination is a cost-effective, definitive, and efficient method that has been used to characterize and identify bacteria (16). The FAME procedure uses a computer software package (Microbial Identification System; Microbial ID, Inc., [MIDI], Newark, DE) and compares quantitative and qualitative differences of constituent bacterial FAMEs. It is rapid, sensitive, and reproducible. Johnk and Jones (7) adapted the MIDI system to characterize fungal cultures when they compared host-specific isolates of $R$. solani AG-1-IA. Additional research showed that FAMEs could be used to separate host-specific isolates of $R$. solani AG-2-2 (8) and AG-3 (10), as well as between isolates of $R$. solani AG-1-IA and AG-1-IC (9).

The objectives were to use FAMEs to characterize and differentiate isolates of $R$. solani AG-4 and AG-7. In addition, FAMEs were used to assess variability and relatedness between the geographical populations of AG-7.

\section{MATERIALS AND METHODS}

Isolates evaluated. In all, 9 isolates of $R$. solani AG-4 and 19 of AG-7 were analyzed for whole-cell fatty acid composition (Table 1). Isolates of $R$. solani AG-4 were included for comparison because this AG is widespread and is considered to be the most economically important $R$. solani AG on agricultural crops in the southeastern United States. All isolates evaluated for fatty acid composition in this study were tested for anastomosis-group affinity by D. E. Carling (University of Alaska-Fairbanks) prior to initiation of the study using previously described methods $(13,17)$. Isolates of RHS 109 and RHS 110 were identified by D. R. Sumner (University of Georgia). 
Cellular fatty acid analysis. Isolates $100 \mathrm{~mm}$ ) containing potato dextrose agar (Difco Laboratories, Detroit) at $27^{\circ} \mathrm{C}$. To prepare the fungal isolates for FAME char(PDB; Difco Laboratories) was added to $500 \mathrm{ml}$ of distilled deionized water conwere initially grown on petri plates (10 by acterization, $12 \mathrm{~g}$ of potato dextrose broth

tained in each flask. Four 3-mm-diameter mycelial plugs were inoculated into flasks containing $500 \mathrm{ml}$ of PDB (pH 5.0) following autoclaving and incubated for 4 days in total darkness at $27^{\circ} \mathrm{C}$. The mycelium mat was removed from the flasks, and $2 \mathrm{~g}$ of the hyphae were weighed, washed with sterile distilled water for 1

Table 1. Isolates, anastomosis group (AG) type, host, and source of Rhizoctonia solani

\begin{tabular}{|c|c|c|c|c|}
\hline Isolate & $\mathbf{A G}^{\mathbf{a}}$ & Host, location ${ }^{b}$ & Isolate reference & Source \\
\hline RB 56 & AG-4 & Cotton, Mississippi & MS 1 & Baird \\
\hline RB 127 & AG-4 & Cotton, Georgia & Floyd 1 & Baird \\
\hline RB 128 & AG-4 & Cotton, Georgia & Floyd 2 & Baird \\
\hline RB 131 & AG-4 & Cotton, Georgia & Floyd 3 & Baird \\
\hline RB 111 & AG-4 & Cotton, Georgia & Tift 1 & Baird \\
\hline RB 23 & AG-4 & Cotton, Georgia & $\mathrm{T}-2 \mathrm{~B}$ & Baird \\
\hline RB 10 & AG-4 & Cotton, Georgia & F.2 & Baird \\
\hline RB 21 & AG-4 & Peanut, Georgia & RHS 109 & Sumner \\
\hline RB 112 & $\mathrm{AG}-4$ & Unknown & RHS 110 & Sumner \\
\hline RB 213 & AG-7 & Cotton, Georgia & Tift 3 & Baird \\
\hline RB 216 & AG-7 & Cotton, Georgia & Mid 3 & Baird \\
\hline RB 17 & AG-7 & Rice, Japan & 1529 & Carling \\
\hline RB 26 & AG-7 & Rice, Japan & 1535 & Carling \\
\hline RB 30 & AG-7 & Rice, Japan & 1556 & Carling \\
\hline RB 691 & AG-7 & Soybean, Mexico & $\ldots$ & Carling \\
\hline RB 31 & AG-7 & Watermelon, Indiana & IN 1 & Baird \\
\hline RB 32 & AG-7 & Watermelon, Indiana & IN 2 & Baird \\
\hline RB 33 & AG-7 & Watermelon, Indiana & IN 3 & Baird \\
\hline RB 20 & AG-7 & Soybean, Arkansas & $92.121 .5 \mathrm{~A}$ & Rothrock \\
\hline RB 18 & $A G-b i^{c}$ & Soybean, Arkansas & 91.815.B & Rothrock \\
\hline RB 651 & AG-7 ST & Soybean, Arkansas & STCH 8057-2A & Rothrock \\
\hline RB 652 & AG-7 ST & Rice, Arkansas & STCH 8159-B & Rothrock \\
\hline RB 653 & AG-7 ST & Rice, Arkansas & STCH 8112-9A & Rothrock \\
\hline RB 25 & AG-7 Pine & Rice, Arkansas & 92.123.B & Rothrock \\
\hline RB 646 & AG-7 Pine & Soybean, Arkansas & PTCH 115A & Rothrock \\
\hline RB 647 & AG-7 Pine & Soybean, Arkansas & PTCH 112-1 & Rothrock \\
\hline RB 648 & AG-7 Pine & Soybean, Arkansas & PAMK 1-20 & Rothrock \\
\hline RB 649 & AG-7 Pine & Soybean, Arkansas & PTCH 123.1AB & Rothrock \\
\hline RB 650 & AG-7 Pine & Soybean, Arkansas & $124-5 \mathrm{~A}$ & Rothrock \\
\hline
\end{tabular}

a $\mathrm{ST}$ refers to the Stuttgart subgrouping and Pine is the Pinetree subgroup of AG-7.

b Cotton (Gossypium hirsutum L.), peanut (Arachis hypogea L.), rice (Oryza sativa L.), watermelon (Citrullus lanatus (Thunb.) Matsum. \& Nakai), and soybean (Glycine max (L.) Merrill.

c Using anastomosis pairing, RB 18, originally believed to be an AG-7, was identified as a binucleate Rhizoctonia sp., but was tested for methyl ester fatty acids compared with the known AG-4 and AG-7 isolate library.

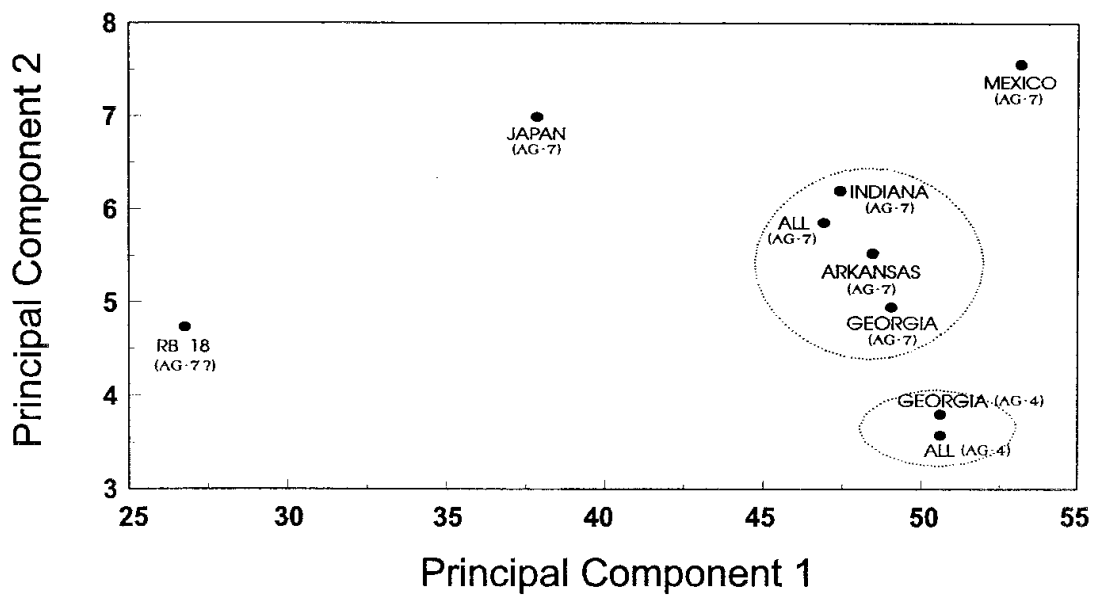

Fig. 1. Plot of the first two principle components derived from the fatty acid compositions (of all detected fatty acids) of Rhizoctonia solani anastomosis group (AG)-7 and AG-4. Symbols represent the mean for each population. Georgia AG-4 includes fatty acid methyl esters (FAME) data for all isolates of AG-4 compared from Georgia. The FAME data were compared by geographic location in several ways, including all Arkansas isolates (Pinetree and Stuttgart subgroups), all Indiana isolates, all Georgia AG-7, all Japan, and total AG-7; total AG-4 and Georgia AG-4 data were compared in the principle components analysis. min, and placed into a screwtop test tube (13 by $100 \mathrm{~mm}$ ) for fatty acid extraction using previously described methods (8). FAME compositions were determined for each isolate. Each isolate was evaluated five times.

FAME composition was determined by gas chromatography procedures (HewlettPackard application note 228-41; HewlettPackard, Pittsburgh) and adapted for $R h i$ zoctonia spp. (7). Principal component analysis was performed on percent FAME composition employing the statistical package provided in the Microbial ID software (MIDI). The methods to derive principal component values have been previously described (15).

Library generations. A composite profile for each AG and geographical subgroup within AG-7 was generated based on the composition of each of five replicates for each isolate and stored as a library reference strain. Individual profiles were compared to library reference strains and relative similarity indices utilizing Euclidean distances were computed. A dendrogram was constructed using the unweighted pair-group method to determine relatedness or differences among entries.

\section{RESULTS AND DISCUSSION}

Johnk and Jones (9) used principle component analysis to separate isolates of AG1-IC from AG-1-IA in 2- to 4-day-old cultures. In that study, it was determined that FAME content and quantity between 2 and 4-day-old cultures was not significantly different. Several isolates did not form $2 \mathrm{~g}$ of mycelium at 2 or 3 days on PDB; therefore, all isolates were grown for 4 days in this investigation.

Eight common FAMEs, ranging from $\mathrm{C} 14$ to $\mathrm{C} 18$, were present in one or more of the $R$. solani AG-4 and AG-7 isolates tested in this study (Table 2). Palmitic (16:0), oleic (18.1 cis 9), and stearic (18:0) acids comprised $95 \%$ of all the FAMEs detected in both anastomosis groups. Lauric (12:0), nonadencanoic (19:0 cyclo W8O), and eicosanoic (20:0) acids were infrequently identified fatty acids (data not shown). Specific whole-cell fatty acids of the two anastomosis groups and the geographical isolates of $R$. solani AG-7 were similar in this study. In previous studies, linoleic and palmitic acids were the two most common FAMEs detected in isolates of $R$. solani AG-1-IA, AG 2-2, and AG-3 (8). However, linoleic acid was absent in the AG-4 and AG-7 isolates evaluated in this investigation. One reason may be that differences in culture methods (e.g., solid versus liquid media) between the current study and previous investigations may have affected the individual FAMEs present in the isolates.

The $R$. solani AG-4 isolates were distinct from $R$. solani AG-7 isolates when the principal components 1 and 2 were plotted using cluster analysis (Fig. 1). Re- 
sults from this analysis also showed that the Arkansas, Georgia, and Indiana isolate values were similar to the mean AG-7 percentages. The three $R$. solani AG-7 isolates from Japan and one from Mexico also were distinct from isolates of AG-4 and AG-7 from other geographical locations. The Georgia AG-7 isolate means fell between the $R$. solani AG-4 and AG-7 mean isolate percentages (principal component 1 accounted for $49.9 \%$ and principal component 2 accounted for 16.0\%). A previous study comparing the effects of temperature on radial growth showed that the AG-7 isolates from Japan grew at a significantly faster rate at $35^{\circ} \mathrm{C}$ than the AG-4 isolates, but the rate was significantly greater only when compared to the Arkansas and Indiana AG-7 isolates (2). In that study, cultural characteristics of AG-7 isolates were similar between the different geographical isolates of AG-7, but several morphological differences in culture were noted between AG-7 and AG-4 isolates.

Anastomosis pairing was conducted to confirm the identity of all isolates evaluated in this study (D. E. Carling, unpublished data). Isolate RB 18 was identified with anastomosis pairing as a binucleate Rhizoctonia sp. The principal component analysis also confirmed that RB 18 did not belong to AG-7 (data not shown). All AG7 isolates were found to be classified into two subgroups based on the anastomosis reactions. One subgroup, AG-7-1, comprises isolates from Japan, Arkansas (Stut- tgart Group, Table 1), and Indiana. The second group, AG-7-2, contains isolates from Arkansas (Pinetree Group, Table 1), Georgia, and Mexico. The Arkansas isolates of AG-7-1 included RB 651, 652, and 653 and the AG-7-2 isolates were RB 25, 646, 647, 648, 649, and 650 .

To verify the results from the anastomosis pairing, the FAMEs for the Arkansas isolates were evaluated using principal component analysis to determine if the whole-cell fatty acid profiles could be used to separate the two subgroups AG-7-1 and AG-7-2 (Fig. 2). Principal components 2 and 3 were compared and accounted for 41.3 and $20.3 \%$, respectively. The Arkansas isolates of $R$. solani AG-7, including RB 652 and 653, formed a separate clus-

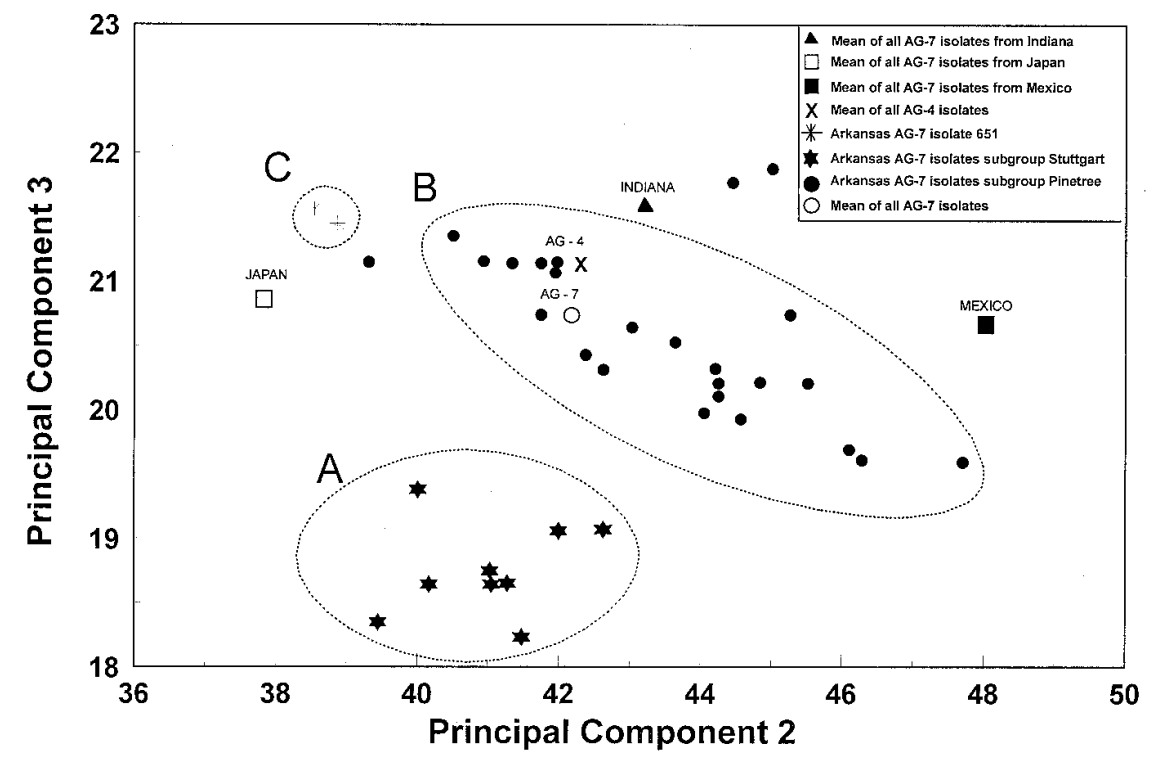

Fig. 2. Plot of the second and third principle components derived from the fatty acid compositions (of all detected fatty acids) of individual isolates of Rhizoctonia solani anastomosis group (AG)-7 (subgroups AG-7-1 and AG-7-2) and AG-4.

Table 2. Percentage of total fatty acid methyl esters (FAMEs) for Rhizoctonia solani isolates of AG-4 and AG-7 on potato dextrose agar

\begin{tabular}{|c|c|c|c|c|c|c|c|c|c|}
\hline \multirow[b]{2}{*}{ Fungi, isolate } & \multirow[b]{2}{*}{ Location $^{a}$} & \multicolumn{8}{|c|}{ Relative \% FAME present } \\
\hline & & 14:0 & $15: 0$ & 15:0A & $16: 0$ & $16: 0 W$ & 17:1W & 18:0 & 18:1W \\
\hline \multicolumn{10}{|l|}{ AG-4 } \\
\hline RB 10 & GA & 0.5 & 0.9 & 1.1 & 12.0 & 0.0 & 0.0 & 1.3 & 13.1 \\
\hline RB 127 & GA & 0.0 & 0.5 & 0.0 & 10.9 & 0.0 & 0.0 & 1.9 & 14.5 \\
\hline RB 128 & GA & 0.0 & 0.0 & 0.0 & 11.6 & 0.0 & 0.0 & 2.2 & 15.0 \\
\hline RB 131 & GA & 0.0 & 0.0 & 0.0 & 10.7 & 0.0 & 0.0 & 1.3 & 11.7 \\
\hline RB 56 & MS & 0.0 & 0.0 & 0.0 & 10.0 & 0.0 & 0.0 & 1.2 & 14.1 \\
\hline RB 21 & GA & 0.3 & 0.6 & 1.2 & 13.6 & 0.0 & 0.0 & 3.2 & 19.5 \\
\hline RB 111 & GA & 0.0 & 0.0 & 0.0 & 9.5 & 0.0 & 0.0 & 1.3 & 14.2 \\
\hline RB 23 & GA & 0.0 & 0.5 & 0.0 & 11.0 & 0.0 & 0.0 & 2.1 & 16.4 \\
\hline Average & $\ldots$ & 0.1 & 0.3 & 0.2 & 11.0 & 0.0 & 0.0 & 1.4 & 13.9 \\
\hline \multicolumn{10}{|l|}{ AG-7 } \\
\hline RB 652 & $\mathrm{AK}$ & 0.5 & 0.4 & 0.0 & 19.7 & 0.0 & 0.0 & 2.9 & 24.1 \\
\hline RB 653 & $\mathrm{AK}$ & 0.0 & 0.5 & 0.0 & 10.7 & 0.0 & 0.0 & 8.8 & 16.2 \\
\hline RB 646 & $\mathrm{AK}$ & 0.0 & 0.5 & 0.0 & 10.8 & 0.3 & 0.0 & 1.8 & 18.1 \\
\hline RB 20 & AK & 0.0 & 0.0 & 0.0 & 10.2 & 0.0 & 0.0 & 1.9 & 18.6 \\
\hline RB 25 & $\mathrm{AK}$ & 0.0 & 0.0 & 0.0 & 13.7 & 0.0 & 0.0 & 2.8 & 20.2 \\
\hline RB 649 & $\mathrm{AK}$ & 0.0 & 0.7 & 0.0 & 8.9 & 0.0 & 0.0 & 1.0 & 13.3 \\
\hline RB 650 & AK & 0.0 & 0.6 & 0.0 & 8.7 & 0.0 & 0.0 & 1.1 & 16.5 \\
\hline RB 648 & $\mathrm{AK}$ & 0.0 & 0.6 & 0.0 & 9.4 & 0.0 & 0.0 & 1.3 & 15.6 \\
\hline RB 647 & $\mathrm{AK}$ & 0.4 & 0.7 & 0.0 & 10.2 & 0.0 & 0.0 & 1.6 & 17.5 \\
\hline RB 484 & GA & 0.0 & 0.5 & 0.0 & 9.8 & 0.0 & 0.0 & 3.3 & 16.3 \\
\hline RB 33 & IN & 0.0 & 0.0 & 0.0 & 8.5 & 0.0 & 0.0 & 2.6 & 13.4 \\
\hline $\mathrm{RB} 480$ & GA & 0.0 & 0.0 & 0.0 & 10.1 & 0.0 & 0.0 & 2.2 & 13.7 \\
\hline RB 31 & IN & 0.0 & 0.0 & 0.0 & 8.7 & 0.0 & 0.0 & 1.8 & 16.0 \\
\hline RB 32 & IN & 0.0 & 0.0 & 0.0 & 10.6 & 0.0 & 0.0 & 2.1 & 18.3 \\
\hline RB 17 & $\mathrm{JP}$ & 0.5 & 1.1 & 0.0 & 13.6 & 0.0 & 0.7 & 2.9 & 22.2 \\
\hline RB 33 & $\mathrm{JP}$ & 0.6 & 0.9 & 0.0 & 13.4 & 0.0 & 0.6 & 2.5 & 23.8 \\
\hline RB 26 & $\mathrm{JP}$ & 0.6 & 1.1 & 0.0 & 13.5 & 0.0 & 0.7 & 2.2 & 19.4 \\
\hline RB 691 & MX & 0.0 & 0.0 & 0.0 & 7.7 & 0.0 & 0.0 & 1.6 & 17.3 \\
\hline Average & $\ldots$ & 0.2 & 0.5 & 0.0 & 11.2 & $<0.1$ & 0.2 & 2.1 & 16.0 \\
\hline
\end{tabular}

${ }^{\mathrm{a}}$ Location of collected isolates: GA = Georgia, AK = Arkansas, IN = Indiana, JP = Japan, MS = Mississippi, and MX = Mexico. 


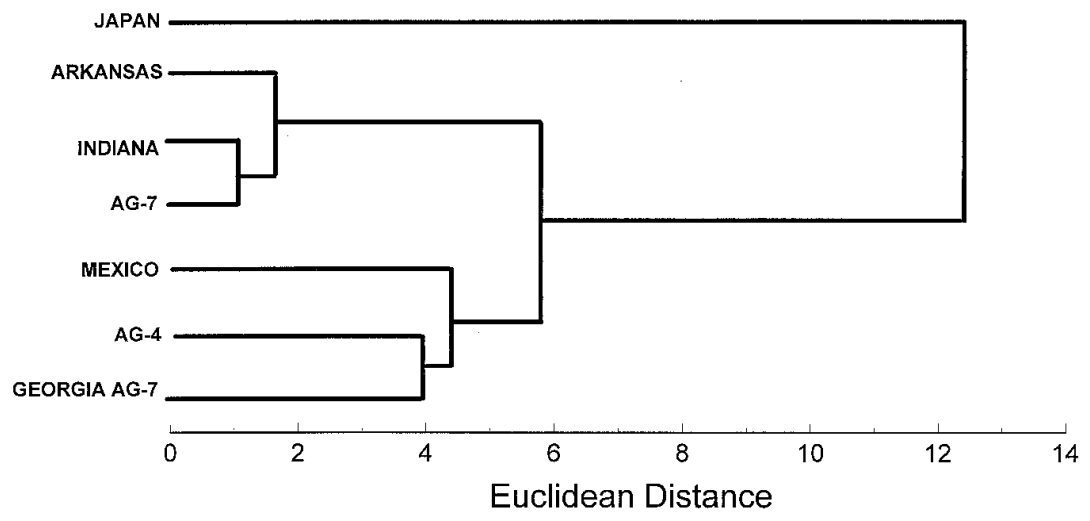

Fig. 3. Dendrogram of Rhizoctonia solani anastomosis group (AG)-7 and AG-4 populations, based on the fatty acid composition of 3 isolates each from Indiana (RB 31, RB32, and RB 33) and Japan (RB 17, RB 26, and RB 30), 1 from Mexico (RB 56), 10 AG-7 isolates from Arkansas (RB 20, RB 25, RB 646, RB 647, RB 648, RB 649, RB 650, RB 651, RB 652, and RB 653), and 2 isolates from Georgia (RB 213 and RB 216) for each intraspecific group grown on potato dextrose broth.

ter from the isolates in subgroup AG-7-1. Results from the cluster analysis corresponded to the anastomosis pairing data. Isolate RB 651 did not show a correlation with either subgroup cluster of $R$. solani AG-7 and confirms the results from anastomosis pairing. The isolates from Indiana, Japan, and Mexico were distinct from the two Arkansas isolate cluster subgroupings.

A dendrogram of the population library entries generated from detectable FAMEs confirmed that $R$. solani AG-7 isolates from Japan and Mexico were distinct from other geographical isolates of AG-7 and all AG-4 isolates (Fig. 3). These results are similar to the principle component cluster analysis shown in Figure 1. The isolates from Indiana and Arkansas with Euclidean distances of 1.4 and 1.5 , respectively, were closest to the mean for all AG-7 isolates. The Georgia isolates of AG-7 were distinct from all other geographical isolates of AG7 shown on the dendrogram. Furthermore, the Euclidean distance of the Georgia AG7 isolates was the same as the $R$. solani AG-4 isolates.
The cluster analysis and dendrogram showing Euclidean distance were effective in separating AG-4 and AG-7 isolates and subgroups of AG-7 geographical isolates. Additional AG-7 isolates from different geographical regions within the United States and other countries should be evaluated to further investigate the variability of FAMEs by locations when they become available.

\section{LITERATURE CITED} rence of Rhizoctonia solani AG-7 in Indiana. Plant Dis. 79:320.

2. Baird, R. E., Carling, D. E., and Mullinix, B. G. 1996. Characterization and comparison of isolates of Rhizoctonia solani AG-7 from Arkansas, Indiana, and Japan and select AG-4 isolates. Plant Dis. 80:1421-1424.

3. Buckner, B., Novotny, C. P., and Ullrich, R. C. 1988. Organization of the ribosomal RNA genes of Schizophyllum commune. Curr. Genet. 13:417-424.

4. Carling, D. E. 1996. Grouping in Rhizoctonia solani by hyphal anastomosis reaction. Pages 37-47 in: Rhizoctonia Species: Taxonomy, Molecular Biology, Ecology, Pathology and Disease Control. B. Sneh, S. Jubaji-Hare, S.
1. Baird, R. E., and Carling, D. E. 1994. Occur-
Neate, and G. Dijst, eds. Klumer Academic Publishers, Dordrecht-Boston-London.

5. Carling, D. E., and Kuninaga, S. 1990. DNA base sequence homology in Rhizoctonia solani Kühn: Inter and intragroup relatedness of anastomosis group-9. Phytopathology 80:1362-1364.

6. Carling, D. E., Kuninaga, S., and Leiner, R. H. 1988. Relatedness within and among intraspecific groups of Rhizoctonia solani: A comparison of grouping by anastomosis and DNA hybridization. Phytoparasitica 16:209210.

7. Johnk, J. S., and Jones, R. K. 1992. Determination of whole-cell fatty acids in isolates of Rhizoctonia solani AG-1 IA. Phytopathology 82:68-72.

8. Johnk, J. S., and Jones, R. K. 1993. Differentiation of populations of AG-2-2 of Rhizocto nia solani by analysis of cellular fatty acids. Phytopathology 83:278-283.

9. Johnk, J. S., and Jones, R. K. 1994. Comparison of whole-cell fatty acid compositions in interspecific groups of Rhizoctonia solani AG-1. Phytopathology 84:271-275.

10. Johnk, J. S., Jones, R. K., Shew, H. D., and Carling, D. E. 1993. Characterization of populations of Rhizoctonia solani AG-3 from potato and tobacco. Phytopathology 83:854858

11. Lui, Z. L., and Sinclair, J. B. 1992. Genetic diversity of Rhizoctonia solani anastomosis group 2. Phytopathology 82:778-787.

12. May, B., and Royce, D. 1988. Infraspecific allozyme variation within the fungi genus Pleurotus. Trans. Br. Mycol. Soc. 90:29-36.

13. Ogoshi, A. 1987. Ecology and pathogenicity of anastomosis and intraspecific groups of Rhizoctonia solani Kuehn. Annu. Rev. Phytopathol. 25:125-143.

14. Rothrock, C. S., Winters, S. A., Kinney, P. M., and Carling, D. E. 1993. Occurrence of Rhizoctonia solani (Thanatephorus cucumeris) AG-7 in Arkansas. Plant Dis. 77:1262.

15. SAS Institute. 1989. Pages 209-244 (v-1) and 891-996 (v-2) in: SAS/STAT User's Guide, version $\mathrm{C}$, 4th ed. SAS Institute, Inc., Cary, NC.

16. Sasser, J. M., Fieldhouse, D. J., and Carter, C N. 1984. Computer assisted identification of bacteria based on fatty acid analysis. Phytopathology 74:882.

17. Sneh, B., Burpee, L., and Ogoshi, A. 1991. Identification of Rhizoctonia solani species. APS Press, The American Phytopathological Society, St. Paul, MN. 